\title{
Diagnosis and treatment of non-infectious and infectious foal diarrhoea
}

\author{
Bettina Dunkel \\ The Royal Veterinary College, North Mymms, UK
}

\begin{abstract}
Diagnose und Behandlung nicht infektiöser und infektiöser Durchfallerkrankungen beim Fohlen
Durchfallerkrankungen sind ein häufiges Problem beim heranwachsenden Fohlen. Nicht-infektiöse Durchfallursachen beinhalten unter anderem während der Zeit der Fohlenrosse auftretende und ernährungsbedingte Durchfälle. Die Erkrankungen sind meist mild und selbstlimitierend und bedürfen keiner speziefischen Behandlung. Gastroduodenalgeschwüre sind selten mit Durchfall verbunden und beheben sich mit Behandlung des Primärproblems. Schwerwiegende, oft multi-systemische Erkrankungen, die intensive medizinische Versorgung erfordern, sind mit hypoxisch-ischämischer Enteropathie und nekrotisierender Enterokolitis verbunden. Seit langem bekannte infektiöse Durchfallerreger umfassen Rotaviren, Salmonella spp. und Cryptosporidien, deren Diagnose mit Hilfe von kommerziellen Testkits und mikrobakterieller oder parasitologischer Kotprobenuntersuchung erstellt werden kann. Die Diagnose von Erkrankungen verursacht durch Clostridium difficile oder perfringens ist schwieriger, da der Erreger bei gesunden, wie auch bei erkrankten Fohlen vorkommen kann. Neben symptomatischer Behandlung, die hauptsächlich in der Korrektur von Flüssigkeits- und Elektrolyteverlusten sowie im Ausgleich des SäureBasenhaushalts besteht, sind evt. bei Clostridiosen Metronidazol, Di-tri-octahedral smectite und Saccharomyces boulardii hilfreich. Ältere Fohlen können an Gewichtsverlust, Hypoproteinämie und Durchfall verursacht durch kleine Strongyliden oder Lawsonia intracellularis leiden. Während der Nachweis von kleinen Strongyliden intra vitam schwierig ist, kann L. intracellularis durch Antikörper im Serum oder durch PCR an Kotproben nachgewiesen werden. Die Therapie beinhaltet Fenbendazol in kleinen laviziden Dosen und lipophile Antibiotika.
\end{abstract}

Schlüsselwörter: Fohlen, Fohlendurchfall, Enterokolitis, Enteritis

\section{Summary}

Diarrhoea is a common problem affecting foals of all ages. Common non-infectious causes of mild to moderate diarrhoea include foal heat diarrhoea and nutritionally induced diarrhoea. Clinical signs often resolve spontaneously without or with only minimal treatment. Gastroduodenal ulceration rarely presents as diarrhoea and resolves once the underlying cause is corrected. Neonatal foals may suffer from hypoxicischaemic enteropathy and necrotising enterocolitis; both are associated with severe, often multi-systemic disease and require intensive medical therapy. Long established infectious causes of foal diarrhoea include rotavirus, Salmonella spp. and Cryptosporidium. Diagnosis can be established using commercially available assays, consecutive faecal cultures or PCR and acid fast faecal staining, respectively. Recent evidence suggests that Clostridium difficile and perfringens may be part of the normal gastrointestinal flora of equine neonates, but can also be associated with cases of mild to severe, and even fatal diarrhoea. Due to their occurrence in normal and diseased animals, diagnosis is difficult and further investigations are required to document their role in foal diarrhoea. Correction of fluid, electrolyte and acid-base abnormalities is the most important treatment of diarrhoea regardless of the underlying aetiology and, depending on age and physiological status, systemic antimicrobials and nutritional support. Although controlled clinical trials are lacking, there is some limited evidence suggesting that treatment with metronidazole, di-tri-octahedral smectite and Saccharomyces boulardii may be beneficial in foals suffering from clostridial diarrhoea. Infectious agents affecting older foals include small strongyles and Lawsonia intracellularis, both more recently recognized pathogen causing weight loss, severe hypoproteinaemia and mild to severe diarrhoea. While diagnosis of cyathostomiasis is difficult to establish intra vitam, L. intracellularis may be diagnosed by serology or identification of the organism by faecal PCR. Treatment consists of larvicidal doses of fenbendazole and systemic antimicrobials with excellent intracellular penetration, respectively.

Key words: Foal, neonate, enteritis, enterocolitis, diarrhoea

\section{Introduction}

Diarrhoea is a common problem affecting foals of all ages with the risk being highest in foals less than 7 days old (Cohen 1994). Although frequently mild and self-limiting, the disease has the potential to progress rapidly and to develop into a life threatening problem. Some infectious agents have the ability to spread rapidly amongst a susceptible population, potentially affecting multiple foals on one farm and, once established on a premise, may reoccur during successive foaling seasons, increasing the work-load and causing significant economic damage. Furthermore, some infectious agents have zoonotic potential, namely Salmonella spp. and
Cryptosporidium, and, under certain circumstances, clostridial species demanding additional protective measures to prevent transmission to caretakers and veterinarians dealing with diseased animals. Rapid and accurate identification of the offending organism is therefore necessary, although sometimes challenging. Unfortunately, clinical signs and laboratory findings in diarrhoeic foals are similar, regardless of the underlying aetiology, making diagnoses based solely on clinical presentation almost impossible and additional diagnostic tests essential for identification of the organism involved. To complicate matters further, some agents can be found in normal and diseased animals alike, have fastidious growth requirements when cultured, or may not be recognized by 
laboratories not accustomed to horse specimens. A thorough knowledge of the prevalence of an organism in a population of healthy individuals as well as diagnostic tests available for a given organism and their sensitivity and specificity are therefore essential and have been reviewed previously (Dunkel and Wilkins 2004). This review article summarises the most common non-infectious and infectious causes of diarrhoea in foals, discusses diagnostic options, describes supportive care for diarrhoeic foals and discusses specific treatments available against offending organisms.

\section{Supportive treatment for foals with diarrhoea}

In any foal with diarrhoea the most important treatment goal, regardless of the aetiology, is maintaining a normal electrolyte, fluid and acid-base balance. In neonatal foals, monitoring and sustaining normal cardiovascular function, prevention of secondary infections and provision of adequate nutrition presents additional therapeutic challenges. The specific requirements of the neonatal foal are addressed in a separate article describing supportive care for the weak and septic neonate.

Before treatment is initiated, blood samples should be obtained for determination of electrolyte and acid-base status, total plasma protein concentration (TP) and a complete blood count (CBC); in foals less than 1 months of age, a sterile blood sample for blood culture should be collected and in neonatal foals serum $\lg G$ concentration should also be determined. The most common electrolyte abnormalities encountered are hyponatraemia, which can be profound and lifethreatening in itself, hypocalcaemia and, less frequently, hypochloraemia (East et al. 1998, MacKay 2001). Lactic acidosis is a common finding due to rapid fluid loss leading to hypovolaemia, dehydration and poor peripheral perfusion. Prerenal azotaemia, hypo-, normo-, or hyperglycaemia and hypo-, normo-, or hyperproteinaemia may be identified. TP concentration and packed cell volume (PCV) need to be viewed in light of the hydration status, as severe dehydration may mask hypoproteinaemia and anaemia. A CBC may reveal leucocytosis or, more commonly, leucopenia with an increased percentage of band neutrophils (East et al. 1998, MakKay 2001, Magdesian et al. 2002).

If hypovolaemia is identified, initial fluid resuscitation should be aimed at replacing existing deficits rapidly to establish normal perfusion as quickly as possible. A balanced, glucosefree electrolyte solution given as fluid boluses of $10-20 \mathrm{ml} / \mathrm{kg}$ over 15-20min is an adequate choice as initial resuscitation fluid. Some clinicians prefer a combination of crystalloids and colloids for resuscitation to achieve greater and longer lasting expansion of the intravascular volume. Equine plasma $(10 \mathrm{ml} / \mathrm{kg} / \mathrm{h}$ with a total volume of $1.0-2.0 \mathrm{~L})$ or a synthetic colloid, such as heta- or pentastarch $(3-5 \mathrm{ml} / \mathrm{kg}$ as a bolus up to a maximum of $10 \mathrm{ml} / \mathrm{kg} / \mathrm{d}$ ) may be used for this purpose (Magdesian 2005). After each bolus, hydration and peripheral perfusion of the patient should be assessed and additional boluses given as needed, up to approximately $80 \mathrm{ml} / \mathrm{kg} / \mathrm{h}$. Once normovolaemia is established, the fluid therapy plan consists of providing maintenance requirements and replacing ongoing losses. Although some authors suggest lower maintenance needs for neonatal foals without diarrhoea (Pal- mer 2004), $80-120 \mathrm{ml} / \mathrm{kg} / \mathrm{d}$ are widely used as an estimate for the daily fluid requirements of foals and may be most appropriate for diarrhoeic foals (Hepburn 2007). Estimated fluid losses are added to the maintenance requirements and the total calculated fluid volume can be given as a constant rate infusion or divided into 4-8 boluses per day. As ongoing fluid losses are difficult to approximate and may vary throughout the day, foals need to be assessed frequently and the fluid plan adjusted as necessary.

Due to the compromise of the gastrointestinal barrier and the possibility of bacterial translocation, broad spectrum antimicrobials, such as a combination of a $\beta$-lactam and an aminoglycoside or a cephalosporin with extended gram-negative coverage, are recommended in any compromised foal (Magdesian 2005); depending on the severity of the underlying condition, either oral or intravenous administration can be chosen. Due to the relatively small muscle mass of foals in comparison to adult horses, multiple intramuscular injections should be avoided. If hypoproteinaemia is severe or lgG concentrations low, intravenous plasma or, if a low oncotic pressure is the main concern, alternatively a synthetic colloid can be administered.

Many diarrhoeic foals continue to nurse and, as long as the foal is haemodynamically stable and able to stand and nurse effectively, should be allowed to do so. Depressed, recumbent or haemodynamically unstable foals require nutritional support either by supplementary enteral feedings of milk or milk replacer by nasogatric tube or by supplying intravenous glucose or parenteral nutrition. The caloric requirements of a healthy, active, growing foal are approximately $100-170 \mathrm{kcal} / \mathrm{kg} / \mathrm{d}$, while provision of maintenance requirements of $40-50 \mathrm{kcal} / \mathrm{kg} / \mathrm{d}$ is probably more appropriate for a compromised neonate (Ousey et al. 1996, Paradis 2001 and 2003).

\section{Non-infectious causes of foal diarrhoea}

\section{Foal heat diarrhoea}

Foal heat diarrhoea is a descriptive term applied to mild, selflimiting diarrhoea occurring in temporal association with the mare's first oestrus 5-15 days after parturition. Although the exact cause has not been established, the diarrhoea is currently thought to be hypersecretory in origin and most likely associated with the establishment of a normal gastrointestinal flora (Masri et al. 1986). Foals remain bright, alert and systemically healthy and specific treatment is not necessary. Diagnosis is established by the combination of mild, self-limiting diarrhoea and the typical age. Signs of systemic disease such as loss of appetite, fever, depression or dehydration indicate a more serious underlying pathophysiology and warrant immediate investigation (Wilkins 2004).

\section{Hypoxic-ischaemic enteropathy}

Neonatal foals, sometimes only a few hours old, may suffer from diarrhoea. The underlying pathophysiology is part of the perinatal asphyxia syndrome (PAS), a syndrome which occurs 
as a result of in utero compromise, intra or post partum complications or failure to adapt rapidly to the extra uterine environment after parturition. One or more organ systems may be affected, such as the central nervous system (hypoxic-ischaemic encephalopathy; HIE), kidneys or the gastrointestinal tract (Wilkins 2004). Organ dysfunction is associated with tissue hypoxia during periods of hypoperfusion and/or hypoxaemia with subsequent reperfusion injury often contributing to organ damage. Clinical signs may be evident shortly after birth or manifest within the first $48 \mathrm{~h}$ of life: signs associated with compromise of the gastrointestinal system include intolerance of enteral feeding, meconium retention, abdominal distension, ileus, mild to moderate colic, nasogastric reflux and passage of watery to bloody faeces (Slovis 2003, Wilkins 2004). Affected foals frequently suffer from multi-systemic problems with weakness, inability to stand and nurse, obtundency or seizures associated with HIE often being the predominating clinical signs. Failure of passive transfer with or without the presence of early sepsis and the inability to maintain normal homoeostatic function such as regulation of blood pressure, glucose metabolism and thermoregulation often complicate the clinical picture. Diagnosis is established by ruling out infectious causes of diarrhoea and is supported by the presence of signs associated with hypoxic-ischaemic damage to other organ systems. These foals require intensive medical therapy and it is often necessary to either withhold enteral feeding completely or only feed very small quantities at the time, a strategy referred to as trophic feeding, in an attempt to stimulated mucosal and intestinal maturation and increase motility and secretion of enteric hormones (Simmer 2007). In either case, parenteral nutrition is an absolute necessity to maintain sufficient caloric intake until the patient is haemodynamically stabile and is able to tolerate adequate quantities of enteral nutrition.

\section{Necrotizing enterocolitis}

Necrotizing enterocolitis (NEC) is a multi-factorial, often life threatening disease of predominantly premature human infants which has been described in foals (Cudd and Pauly 1987, Wehrli Eser et al. 2002). Predisposing factors in human neonates include prematurity, intestinal ischaemiareperfusion injury, enteral feeding and infectious disease. During periods of haemodynamic compromise, cardiac output is redistributed to meet the demands of central organs. As a consequence, blood is shunted away from the mesenteric vasculature and oxygen supply is unable to meet the demand of the tissue, resulting in ischaemic injury and, in the worst cases, ischaemic necrosis of the intestine (Horton 2005). Release of inflammatory cytokines into the circulation and translocation of bacterial products or even bacteria through the increasingly permeable mucosal barrier contribute to the development of sepsis in theses patients. Enteral feeding and infection have also been associated with NEC; feeding may promote overgrowth of potentially pathogenic bacteria; however, the disease has also been described in neonates who have never been fed and no specific bacterial or viral organism has been consistently isolated (Horton 2005, Patole 2007). Clinical presentation in human neonates depends largely on the stage of the disease: Early in the disease process, signs of generalised sepsis such as depression, changes 
in body temperature, feed intolerance with gastrointestinal reflux, ileus, hypotension and glucose instability predominate. Later on, abdominal distension and pain, haemorrhagic diarrhoea and even intestinal perforation with septic peritonitis or pneumoperitoneum may occur. The involvement of gas-producing anaerobic bacteria may account for the development of pneumatosis intestinalis, visible on radiographs or during ultrasonographic examination, in some of the cases (Horton 2005). Clinical signs in foals resemble those described for human neonates closely (Cudd and Pauly 1987, Wehrli Eser et al. 2002). Management of these foals involves treatment of haemodynamic and metabolic instabilities and sepsis; parenteral nutrition is indicated until the patient has stabilised. Surgical resection of affected intestine, as it is commonly done in human neonates, has not been described in foals to the author's knowledge.

\section{Nutritional diarrhoea}

Orphaned or hospitalized foals fed with milk or a milk replacer with a different nutrient composition than mares' milk or with milk replacer which has been made up too dilute or too concentrated may develop mild to moderate diarrhoea. Midlactation milk from mares contains approximately $1.3 \%$ fat, $1.9 \%$ protein, $6.9 \%$ sugar and $50.6 \mathrm{kcal} / 100 \mathrm{ml}$ energy (Oftedal et al. 1983), compared to cows' or goats' milk, the two most commonly used substitutes for mares' milk, contents of fat and protein are lower and lactose concentration is higher. Nutritional diarrhoea may be prevented or limited by feeding of mares' milk whenever possible, gradual introduction of a new feed source and attention to the energy content, composition and preparation of milk replacers used.

Lactose intolerance due to lactase deficiency has also been reported in foals recovering from infectious diarrhoea caused by organisms that affect the small intestinal brush boarder enzymes, most commonly rotavirus or clostridial organisms (Weese et al. 1999). Lactose intolerance may be suspected in any foal with protracted diarrhoea after recovery from enteritis. A definite diagnosis of lactose intolerance can be made by a lactose tolerance test or, alternatively, foals may simply be supplemented with commercially available lactase.

\section{Other causes}

Diarrhoea is an infrequent clinical sign of gastroduodenal ulceration with signs of gastrointestinal discomfort, bruxism, ptyalism and reflux due to mechanical outflow obstruction being far more prevalent (Becht and Byars 1986, Bernard 2004). An association between rotavirus and occasionally Salmonella induced diarrhoea has been anecdotally reported (Becht and Byars 1986), but a definite causative relationship has so far not been demonstrated. As a greater incidence of ulceration has been reported in foals with other clinical disorders or exposed to stressful events (Furr et al. 1992, Murray 1989), foals suffering from diarrhoea may be predisposed to the development of concurrent gastrointestinal ulceration. Many clinicians consider it therefore prudent to treat foals in potentially stressful situations prophylactically with anti-ulcer medications such as histamine type 2 receptor antagonists, proton pump inhibitors or sucralfate. However, others have suggested that in critically ill neonatal foals with haemodynamic disturbances poor perfusion of the gastric mucosa is the main predisposing factor for gastric ulceration and improving perfusion will be sufficient to prevent clinically significant ulceration. This suggestion is supported by the fact that post mortem examination of neonatal foals treated with and without anti-ulcer medications revealed no differences in the occurrence, the subjectively judged severity and location of ulcers between the two groups. As the acidic environment also serves as a protective barrier against colonialisation of the gastrointestinal tract by potentially harmful bacteria, the indiscriminate use of anti-ulcer medications in foals with diarrhoea can not be recommended, but requires careful consideration of the age of the patient, the underlying disease process and expected benefits from the treatment (Wilkins 2004).

Rare cases of diarrhoea induced by ingestion of foreign material, such as sand, have been reported in older foals (Ramey and Reinertson 1984). Diagnosis may be based on the presence of sand in the faeces, abdominal radiographs or ultrasonographic examination. Specific treatment, although controversial due to its lack of proven efficacy in adult horses with experimentally induced sand accumulation, may include psyllium administration in cases of sand induced diarrhoea (Hammock et al. 1998).

\section{Infectious diarrhoea}

\section{Rotavirus}

Rotavirus causes diarrhoea in children and youngsters of many mammalian species; although considered species specific, experimental cross species infection has been reported (Nakagomi and Nakagomi 2002). Group A rotavirus is responsible for most infections occurring in foals aged 1 week up to 3 months, with most cases being identified within the first month of life. Occasionally, disease in younger and older foals has been reported (Browning et al. 1991, Conner and Darlington 1980). The virus is highly contagious and frequently involves multiple animals in a herd (Conner and Darlington 1980); in-contact animals may become subclinically infected (Netherwood et al. 1996). The virus has a specific tropism for the mature enterocytes located at the villus tip of the jejunal and ileal mucosa. Destruction of these cells leads to villus atrophy with subsequent impaired digestion and absorption of nutrients. Undigested nutrients accumulate in the gastrointestinal lumen where they function as osmotically active molecules resulting in water loss into the intestinal lumen and give rise to bacterial fermentation. Replacement of the denuded epithelium of the villus tip by less mature crypt cells additionally favors maldigestion and increased fluid and electrolyte secretion into the enteric lumen (Colbere-Garapin et al. 2007). Diagnosis can be established by virus isolation, electron microscopy or commercially available test kits either based on enzyme immunoassays or latex particle agglutination. Test kits are probably the most practical means of establishing a diagnosis in routine veterinary practice and have been shown to perform with good sensitivity and specificity (Conner et al. 1983, Otto et al. 1997). 
Only $2-8 \%$ of healthy foals have been found to shed rotavirus (Browning et al. 1991) and if the virus is identified in a foal in the appropriate age group with signs of diarrhoea the likelihood of it being the aetiologic agent is high, particularly if multiple animals are involved. As no specific therapy is currently available for treatment of viral enteritis, supportive care of affected foals with replacement of fluids and electrolytes has utmost priority. Depending on the age of the foal and the severity of the disease, systemic antimicrobials are indicated if translocation of bacteria across the damaged mucosa is a concern.

\section{Clostridium perfringens}

Clostridium perfringens is a ubiquitous organism, which can be cultured in moderate to large numbers from up to $90 \%$ of healthy neonatal foals and most likely represents part of the normal microflora of this age group. The prevalence decreases with age, but the organism can still be found in 30-35\% of brood mares and foals 1-2 months of age (Tillotson et al. 2002). The organism is categorized into types A-E based on the expression of one or a combination of major lethal exotoxins. All C. perfringens types produce $\alpha$-toxin which is not thought to be a significant enteric virulence factor (Jones 2000). Enterotoxin, the toxin responsible for food poisoning in man, can be produced by all types, but is most commonly associated with type A (Jones 2000). The toxin is identified in approximately $2-6 \%$ of all Clostridium perfringens isolates (Jones 2000). The role of enterotoxin as a virulence factor in equine gastrointestinal disease remains controversial. Although accounting for only $10 \%$ of isolates from foals, enterotoxigenic strains were significantly associated with diarrhoea in one report (Netherwood et al. 1998b) and enterotoxin was detected in $28 \%$ of foals with diarrhoea, while the toxin or isolates carrying its gene were identified in $0-2 \%$ of normal foals (Tillotson et al. 2002, Weese et al. 2001). Nevertheless, due to its infrequent presence it has been suggested that the toxin alone can not account for the overall association of $\mathrm{C}$. perfringes with diarrhoea in foals (Netherwood et al. 1998b). Beta-toxin, produced by types B and C and $\beta 2$-toxin produced by certain strains of type $A$, have comparable biological activities and $C$. perfringens types $A$ and $\mathrm{C}$ are most frequently associated with diarrhoea in foals while type $B$ and $D$ have been only sporadically reported (Stubbings 1990). Beta-toxin is susceptible to intestinal enzymatic digestion and it has been suggested that trypsin inhibitors present in colostrums may predispose neonates with adequate passive transfer to the pathogenic effects of the toxin (East et al. 1998).

While type $A$, including strains expressing the $\beta 2$-toxin, can be isolated from a large percentage of healthy foals, type C appears to be rarely found in healthy animals (Tillotson et al. 2002) and, if isolated from cases with enterocolitis, the organism is associated with severe disease and a high mortality (East et al. 1998). Most reported cases of enterocolitis in neonatal foals associated with either $C$. perfringens type $A$ or $C$ describe severe, rapidly progressing, often haemorrhagic to necrotizing, enteritis and enterocolitis with marked systemic effects and frequently fatal outcome (Bueschel et al. 1998, Dickie et al. 1978, Drolet et al. 1990, East et al. 1998,
Howard-Martin et al. 1986, Pearson et al. 1986). Clinical signs in these cases reflect the severity of the underlying disease and include colic, alterations in haemogram, electrolyte and acid base status, abnormal peritoneal fluid and intestinal mural emphysema visible on abdominal radiographs or ultrasonographic examination (East et al. 1998). However, a large survey including foals less than 1 year of age in the UK indicated that, although the organism was significantly associated with approximately $50 \%$ of fatal cases recorded, overall fatality was low and most $C$. perfringens-associated diarrhoea cases were not severe (Netherwood et al. 1998b, Netherwood et al. 1996). It is unknown whether this discrepancy indicates an increased pathogenicity of the organism in neonates, as suspected for $C$. perfringens type $C$, or whether its high prevalence in normal neonatal foals may simply make it the most readily isolated and therefore most frequently incriminated organism in severe cases of neonatal enterocolitis.

Definite diagnosis is difficult as large numbers of $\mathrm{C}$. perfringens can be isolated from healthy neonatal foals and no markers for pathogenic sub-population have been identified (Netherwood et al. 1998a, Tillotson et al. 2002). Culture and subsequent genotyping of isolates may be helpful in identifying the presence of $C$. perfringens type $C$, the organism with the most certain association with severe clinical disease in neonatal foals (East et al. 1998, Tillotson et al. 2002). A commercially available ELISA for detection of enterotoxin is frequently used clinically, but the significance of either a positive or negative finding in light of the uncertain role of enterotoxin in foal diarrhoea is questionable. Gram staining has been proposed as a rapid, but crude method to identify large numbers of clostridial organisms of any species in faecal smears, although in approximately $60 \%$ of culture positive samples gram positive rods could not be detected (Tillotson et al. 2002). Unfortunately, the clinical relevance of even a positive finding is minimal.

Early and aggressive treatment including fluid therapy and haemodynamic and nutritional support as necessary is indicated in foals that show systemic signs of disease, as the progression of the disease is rapid and, in the case of C. perfringens type $C$ infection, often fatal despite intensive treatment (East et al. 1998). Specific treatment options for clostridial diarrhoea are discussed below.

\section{Clostridium difficile}

Clostridium difficile has gained increasing attention in recent years as a cause of antimicrobial associated diarrhoea in man and animal species and is currently one of the most important nosocomial pathogens in human hospitals (Keel and Songer 2006). Although the pathogen has been identified in a wide variety of species, lesions may vary between and even within different age groups of one species. In adult horses, intestinal lesions are largely limited to caecum and colon, although the suggestion that $C$. difficile is involved in the pathogenesis of proximal duodenitis-jejunitis has recently resurfaced (Arroyo et al. 2006). Foals suffer from predominantly small intestinal disease, although parts of the large intestine may also be involved (Jones et al. 1988, Keel and Songer 2006, Magdesian et al. 2002). The best described 
virulence factors of the organism include toxin $A$ and $B$, potent enterotoxin and a cytotoxins, respectively, which appear to act synergistically in damaging the intestinal mucosa. Additional effects include initiation of the inflammatory cascade with widespread leucocyte activation, predisposing the host to development of an systemic inflammatory response and sepsis (Keel and Songer 2006). Binary ADP ribosyltransferase (CDT), a third important toxin of $C$. difficile, has been identified in equine isolates (Arroyo et al. 2007, McGurrin et al. 2007). While rarely found in adult horses without signs of gastrointestinal disease or previous antimicrobial treatment, Clostridium difficile and its toxins can be isolated from healthy, neonatal foals and in slightly older foals treated with antimicrobials. One study cultured the organism from 30\% of healthy foals $0-13 d$ old, but prevalence of the organism declined rapidly during the next months of life. However, $15-$ $44 \%$ of foals without signs of gastrointestinal disease previously treated with antimicrobials were found to carry the organism (Baverud et al. 2003). Although implicated as a causative agent of foal diarrhoea since 1987 (Jones et al. 1988, Jones et al. 1987, Weese et al. 1999), the role of C. difficile as a primary enteropathogen in foals with adequate transfer of passive immunity has only recently been demonstrated by Arroyo et al. by successful experimental infection (Arroyo et al. 2004). Clinical signs in these foals varied from none in one foal to mild abdominal discomfort, pasty faeces and, in severely affected animals, colic and watery diarrhoea (Arroyo et al. 2004).

Diagnosis of $C$. difficile associated diarrhoea is most commonly established by either anaerobic culture of the organism with or without subsequent demonstration of either toxin encoding genes by PCR or demonstration of one or both of the main toxins by enzyme immunoassay. Alternatively, faeces may only be screened for the presence of one or both toxins without additional culture. However, definitive diagnosis of C. difficile induced diarrhoea remains difficult. As outlined above, the organism and its toxins can be found in normal neonatal foals less than 2 weeks old and older foals previously treated with antimicrobials, indicating that neither a positive culture nor demonstration of toxin A or B provides definite evidence that $C$. difficile is the primary pathogen. Exclusion of enrolment of the organism is equally challenging as sample handling requires meticulous attention. Survival of C. difficile rapidly declines within 48-72h if samples, stored at $4^{\circ} \mathrm{C}$, are exposed to air (Weese et al. 2000). Although the toxins are more resistant and can be recovered even from samples stored aerobically at $4^{\circ} \mathrm{C}$ for at least $30 \mathrm{~d}$, a single toxin negative sample, particularly if taken early in the disease process may not be sufficient to rule involvement of toxigenic C. difficile out (Arroyo et al. 2004, Weese et al. 2000). Equally, culture and toxin may rapidly become negative within 48-72h after initiation of treatment with metronidazole (Arroyo et al. 2004).

There is some, although limited, evidence in mature horses as well as in foals that metronidazole may be beneficial in cases of suspected or confirmed clostridial diarrhoea (Arroyo et al. 2006, Arroyo et al. 2004, Weese et al. 2006). Foals experimentally inoculated with $C$. difficile became culture and toxin negative 48-72h after initiation of metronidazole therapy, however, a self-limiting effect of the infection could not be ruled out as no untreated control group was investigated
(Arroyo et al. 2004). Resistance to metronidazole has been reported in 19\% of isolates from adult horses and foals and, in another study, in $43 \%$ of isolates obtained from foals (Jang et al. 1997, Magdesian et al. 2002). Antimicrobial resistance appears to depend to a degree on the geographical location, as no resistance was detected in a recent investigation in Sweden (Baverud et al. 2003) and determination of an antimicrobial sensitivity pattern of isolates may be advisable if the organism is frequently encountered or a case does not respond to treatment. Administration of di-tri-octahedral smectite (Bio-spongeTM) may be beneficial as it has been shown to adsorb a large variety of clostridial as well as other enteric toxins in vitro (Lawler et al. 2008, Martirosian et al. 1998, Weese et al. 2003). Although administration of the product to young foals has been anecdotally associated with constipation and colic, the product is used widely without apparent adverse effects. Interference of smectite with absorption of colostral antibodies may occur if the product is administered prophylactically to foals less than $8 \mathrm{~h}$ of age and delay of prophylactic administration on endemic farms for $>6$-8h after ingestion of colostrum has been suggested (Lawler et al. 2008). Further treatment options include oral administration of Saccharomyces boulardii, a non-pathogenic yeast which has been advocated for prevention and treatment of C. difficile associated colitis and other forms of diarrhoea in man; investigation of the yeast in a limited number of horses indicated some potential benefits in adult horses with colitis (Desrochers et al. 2005).

\section{Salmonella}

Salmonella spp. cause enteritis and enterocolitis in horses of all age groups; in foals specifically, the organism is frequently associated with neonatal sepsis with or without diarrhoea and has been significantly associated with severe and often fatal diarrhoea in foals up to 1 year of age (Netherwood et al. 1996). Other manifestations in neonates and older foals include arthritis, osteomyelitis, physitis and a case of septic meningoencephalomyelitis has recently been reported in a neonatal foal (Patterson-Kane et al. 2001). Virulence factors include the ability to adhere to and invade the intestinal mucosa, production of entero- and cytotoxins and stimulation of a severe local and systemic inflammatory response (Murray 2002). Enteroinvasive serotypes may account for the frequently concurrent presence of enteritis/enterocolitis and bacteraemia/sepsis in equine neonates (Magdesian 2005). The prevalence of Salmonella spp. in healthy foals has not been extensively investigated, reports range from $0.02 \%$ to $1 \%$ (Dwyer et al. 1990, Netherwood et al. 1996, Tillotson et al. 2002), but neonatal foals appear to have an increased susceptibility to Salmonella infection and at least one hospital outbreak of salmonellosis could be traced to an infected foal (Schott et al. 2001). Diagnosis relies on guidelines established for adult horses; due to the intermittent shedding pattern 3-5 faecal cultures obtained at 24 hour intervals have been recommended to rule out Salmonella infection with $>90 \%$ confidence (Cohen et al. 1996; Palmer et al. 1985). PCR has been suggested as a useful diagnostic tool for detection of Salmonella shedding due to higher sensitivity, more rapid results and requirement of fewer samples (Amavisit et al. 2001, Cohen et al. 1996). 
However, false negative results may occur due to the presence of inhibitory substances (Amavisit et al. 2001). The high sensitivity of the test may also lead to the detection of non-viable or very low numbers of organisms of unknown clinical significance.

\section{Lawsonia intracellularis}

Lawsonia intracellularis, a gram negative obligate intracellular organism, infects rapidly dividing epithelial crypt cells of predominantly the small, but in some species also parts of the large intestine. In horses, the small intestine is most commonly affected, but lesions can extend to caecum and colon (Frank et al. 1998, Lavoie et al. 2000, Schumacher et al. 2000, Williams et al. 1996). The disease has been reported sporadically in foals and weanlings 3-8 months of age but older animals may also be affected and outbreaks involving several foals have been reported (Deprez et al. 2005, Lavoie et al. 2000, McGurrin et al. 2007). Clinical presentation includes rapid weight loss, poor body condition, lethargy, depression, diarrhoea, mild to severe colic and peripheral oedema, often accompanied by other diseases including parasitism, gastric ulceration, upper airway infection and bronchopneumonia. Hypoproteinaemia is often profound and thickened small intestine may be visualized ultrasonographically (Lavoie et al. 2000, McGurrin et al. 2007, Schumacher et al. 2000). Diagnosis can be based on serology, demonstration of faecal shedding of the organism by PCR or immunoperoxidase staining or, in selected cases, examination of intestinal biopsies (Schumacher et al. 2000). In a recent outbreak, neither PCR nor serologic examination identified all cases involved and concurrent use of both tests may be advisable (McGurrin et al. 2007). Culture of the organism is impractical due to the organism's fastidious growth requirements (Knittel et al. 1998). The organism appears to be sensitive to several lipophilic or amphoteric antimicrobials and erythromycin with or without rifampin, oxytetracycline and doxycycline have been suggested (Sampieri et al. 2006). To combat the severe small intestinal inflammation and thickening, use of corticosteroids may be indicated (McGurrin et al. 2007). Nutritional management can be challenging due to often severe depression and profound inappetance on the one hand and reduced intestinal absorption on the other. An oral glucose absorption test may reveal severely compromised absorptive capacities in some cases and parenteral nutrition may be required until small intestinal function has sufficiently recovered (Dunkel, unpublished observation).

\section{Cryptosporidium}

Cryptosporidium parvum, a coccidial parasite invades the apical border of small intestinal villous epithelial cells in horses. Initially associated with diarrhoea in immuno-compromised foals (Mair et al. 1990, Snyder et al. 1978), mild to severe and occasionally fatal diarrhoea has been recognised in immuno-competent foals as young as $4 \mathrm{~d}$ of age (Gajadhar et al. 1985, Grinberg et al. 2003). Older foals can develop chronic, intermittent diarrhoea, which may be present for several months (Xiao and Herd 1994b).
Cryptosporidium may be identified in $0-31 \%$ of healthy foals from 7 days to 23 weeks of age depending on the diagnostic method employed (Cole et al. 1998, Coleman et al. 1989, Xiao and Herd 1994a). Oocyst excretion starts at around 510 days of age although earlier shedding has been observed, peaks at 5-8 weeks and decreases with age (Cohen and Snowden 1996, Xiao and Herd 1994a). The association between Cryptosporidium shedding and diarrhoea increases with increasing numbers of oocysts detected in the faeces (Netherwood et al. 1996). Diagnosis may be achieved by acid-fast staining of faecal smears, immunofluorescent antibody assays or flow cytometric examination of faecal samples. Multiple samples may be required due to the intermittent shedding pattern (Xiao and Herd 1994a). Although multiple treatments have been investigated, none has been proven to be effective in foals (Cohen and Snowden 1996).

\section{Other parasites}

Strongyloides westeri is one of the first parasites found in foals and diarrhoea has been reported in heavily infested animals (greater than 2000 eggs/gram faeces) (Brown et al. 1997, Netherwood et al. 1996). The prepatent period is 10-12 days and the parasite is spontaneously shed after a few months (Brown et al. 1997, Lyons et al. 2001). Prevalence of the disease has been significantly reduced with regular deworming programs using ivermectin and benzimidazoles (Brown et al. 1997, Ludwig et al. 1983).

Larval cyathostomiasis has gained increasing attention as cause of weight loss, diarrhoea and hypoproteinaemia in equids. Although reported in horses of all ages, younger horses between 1 and 3 years of age appear to be affected more frequently (Lyons et al. 2000, Peregrine et al. 2006). Some species of small strongyles are reported to infect younger foals with the parasites establishing maturity once the animal has reached 6-10 weeks of age (Lyons et al. 2001). The clinical signs observed are thought to be attributed to sudden eruption of large numbers of encysted larvae, although the full pathogenesis is still poorly understood (Lyons et al. 2000). Diagnosis of cyathostomiasis is challenging and definite confirmation can so far only be obtained by post mortem examination or, in selected cases, by examination of large intestinal or rectal biopsies (Love 1992, Peregrine et al. 2006). Faecal examination may reveal $L 4$ larvae and adult parasites in $30 \%$ or strongyle eggs in $36 \%$ of horses with clinical signs compatible with cyathostomiasis, respectively (Smets et al. 1999). Treatment includes larvicidal doses of fenbendazole (10mg/kg for 5 consecutive days) (Lyons et al. 2000).

\section{References}

Amavisit P., Browning G. F., Lightfoot D., Church S., Anderson G. A., Whithear K. G. and Markham P. F. (2001) Rapid PCR detection of Salmonella in horse faecal samples. Vet. Microbiol. 79, 63-74

Arroyo L. G., Staempfli H. and Weese J. S. (2007) Molecular analysis of Clostridium difficile isolates recovered from horses with diarrhea. Vet. Microbiol. 120, 179-183 
Arroyo L. G., Stampfli H. R. and Weese J. S. (2006) Potential role of Clostridium difficile as a cause of duodenitis-proximal jejunitis in horses. J. Med. Microbiol. 55, 605-608

Arroyo L. G., Weese J. S. and Stämpfli H. R. (2004) Experimental Clostridium difficile enterocolitis in foals. J. Vet. Intern. Med. 18, 734-738

Baverud V., Gustafsson A., Franklin A., Aspan A. and Gunnarsson A. (2003) Clostridium difficile: prevalence in horses and environment, and antimicrobial susceptibility. Equine Vet. J. 35, 465-471

Becht J. L. and Byars T. D. (1986) Gastroduodenal ulceration in foals. Equine Vet. J. 18, 307-312

Bernard W. (2004) Colic in the foal. Equine Vet Educ 16, 319-323.

Brown, C.A., MacKay, R.J., Chandra, S., Davenport, D. and Lyons, E.T. (1997) Overwhelming strongyloidosis in a foal. J. Am. Vet. Med. Assoc. 211 , 333-334

Browning G. F., Chalmers R. M., Snodgrass D. R., Batt R. M., Hart C. A., Ormarod S. E., Leadon D., Stoneham S. J. and Rossdale P. D. (1991) The prevalence of enteric pathogens in diarrhoeic thoroughbred foals in Britain and Ireland. Equine Vet. J. 23, 405-409

Bueschel D., Walker R., Woods L., Kokai-Kun J., McClane B. and Songer J. G. (1998) Enterotoxigenic Clostridium perfringens type A necrotic enteritis in a foal. J. Am. Vet. Med. Assoc. 213, 13051307,1280

Cohen N. D. (1994) Causes of and farm management factors associated with disease and death in foals. J. Am. Vet. Med. Assoc. 204, 1644-1651

Cohen N. D., Martin L. J., Simpson R. B., Wallis D. E. and Neibergs H. L. (1996) Comparison of polymerase chain reaction and microbiological culture for detection of salmonellae in equine feces and environmental samples. Am. J. Vet. Res. 57, 780-786

Cohen N. D. and Snowden K. (1996) Cryptosporidial diarrhea in foals. Comp. Cont. Educ. Pract. Vet. 18, 298-306

Colbere-Garapin F., Martin-Latil S., Blondel B., Mousson L., Pelletier I., Autret A., Francois A., Niborski V., Grompone G., Catonnet G. and van de Moer $A$. (2007) Prevention and treatment of enteric viral infections: possible benefits of probiotic bacteria. Microb. Infection/Institut Pasteur 9, 1623-1631

Cole D. J., Cohen N. D., Snowden K. and Smith R. (1998) Prevalence of and risk factors for fecal shedding of Cryptosporidium parvum oocysts in horses. J. Am. Vet. Med. Assoc. 213, 1296 1302

Coleman S. U., Klei T.R., French D. D., Chapman M. R. and Corstvet R. E. (1989) Prevalence of Cryptosporidium sp in equids in Louisiana. Am. J. Vet. Res. 50, 575-577

Conner M. E. and Darlington R. W. (1980) Rotavirus infection in foals. Am. J. Vet. Res. 41, 1699-1703

Conner M. E., Gillespie J. H., Schiff E. I. and Frey M. S. (1983) Detection of rotavirus in horses with and without diarrhea by electron microscopy and Rotazyme test. Cornell Vet. 73, 280-287

Cudd T. and Pauly T. (1987) Necrotizing enterocolitis in two equine neonates. Comp. Cont. Educ. Pract. Vet 9, 88-96

Deprez P., Chiers K., Gebhart C. J., Ducatelle R., Lefere L., Vanschandevijl K. and van Loon G. (2005) Lawsonia intracellularis infection in a 12-month-old colt in Belgium. Vet. Rec. 157, 774-776

Desrochers A.M., Dolente B.A., Roy M.F., Boston R. and Carlisle S. (2005) Efficacy of Saccharomyces boulardii for treatment of horses with acute enterocolitis. J. Am. Vet. Med. Assoc. 227, 954-959

Dickie C. W., Klinkerman D. L. and Petrie R. J. (1978) Enterotoxemia in two foals. J. Am. Vet. Med. Assoc. 173, 306-307

Drolet R., Higgins R. and Cecyre A. (1990) Necrohemorrhagic enterocolitis caused by Clostridium perfringens type $C$ in a foal. Can. Vet. J. $31,449-450$

Dunkel B. and Wilkins P. A. (2004) Infectious foal diarrhoea: pathophysiology, prevalence and diagnosis. Equine Vet. Educ. 16, 94-101

Dwyer R.M., Pavell D.G., Roberts W., Donahue M., Lyons E.T., Osborne M. and Woode G. (1990) A study of the etiology and control of infectious diarrhea among foals in central Kentucky. Proc. Am. Ass. Equine Pract, 337-355
East L. M., Savage C. J., Traub-Dargatz J. L., Dickinson C. E. and Ellis R. P. (1998) Enterocolitis associated with Clostridium perfringens infection in neonatal foals: 54 cases (1988-1997). J. Am. Vet. Med. Assoc. 212, 1751-1756

Frank N., Fishman C. E., Gebhart C. J. and Levy M. (1998) Lawsonia intracellularis proliferative enteropathy in a weanling foal. Equine Vet. J. 30, 549-552

Furr M. O., Murray M. J. and Ferguson D. C. (1992) The effects of stress on gastric ulceration, T3, T4, reverse T3 and cortisol in neonatal foals. Equine Vet. J. 24, 37-40

Gajadhar A. A., Caron J. P. and Allen J. R. (1985) Cryptosporidiosis in Two Foals. Can. Vet. J. 26, 132-134

Grinberg A., Oliver L., Learmonth J. J., Leyland M., Roe W. and Pomroy W. E. (2003) Identification of Cryptosporidium parvum 'cattle' genotype from a severe outbreak of neonatal foal diarrhoea. Vet. Rec. 153, 628-631

Hammock P. D., Freeman D. E. and Baker G. J. (1998) Failure of psyllium mucilloid to hasten evaluation of sand from the equine large intestine. Vet. Surg. 27, 547-554

Hepburn R. (2007) Management of diarrhoea in foals up to weaning. In Practice 29, 334-341

Horton K. K. (2005) Pathophysiology and current management of necrotizing enterocolitis. Neonatal. Netw. 24, 37-46

Howard-Martin M., Morton R. J., Qualls C. W. Jr. and MacAllister C. $G$. (1986) Clostridium perfringens type $C$ enterotoxemia in a newborn foal. J. Am. Vet. Med. Assoc. 189, 564-565

Jang S. S., Hansen L. M., Breher J. E., Riley D. A., Magdesian K. G., Madigan J. E., Tang Y. J., Silva J. Jr. and Hirsh D. C. (1997) Antimicrobial susceptibilities of equine isolates of Clostridium difficile and molecular characterization of metronidazole-resistant strains. Clin Infect Dis 25 Suppl 2, S266-267

Jones R. L. (2000) Clostridial enterocolitis. Vet. Clin. North. Am. Equine Pract. 16, 471-485

Jones R. L., Adney W. S., Alexander A. F., Shideler R. K. and TraubDargatz J. L. (1988) Hemorrhagic necrotizing enterocolitis associated with Clostridium difficile infection in four foals. J. Am. Vet. Med. Assoc. 193, 76-79

Jones R. L., Adney W. S. and Shideler R. K. (1987) Isolation of Clostridium difficile and detection of cytotoxin in the feces of diarrheic foals in the absence of antimicrobial treatment. J. Clin. Microbiol. 25, 1225-1227

Keel M. K. and Songer J. G. (2006) The comparative pathology of Clostridium difficile-associated disease. Vet. Pathol. 43, 225-240

Knittel J. P., Jordan D. M., Schwartz K. J., Janke B. H., Roof M. B., McOrist S. and Harris D. L. (1998) Evaluation of antemortem polymerase chain reaction and serologic methods for detection of Lawsonia intracellularis-exposed pigs. Am. J. Vet. Res. 59, 722726

Lavoie J. P., Drolet R., Parsons D., Leguillette R., Sauvageau R., Shapiro J., Houle L., Halle G. and Gebhart C. J. (2000) Equine proliferative enteropathy: a cause of weight loss, colic, diarrhoea and hypoproteinaemia in foals on three breeding farms in Canada. Equine Vet. J. 32, 418-425

Lawler J. B., Hassel D. M., Magnuson R. J., Hill A. E., McCue P. M. and Traub-Dargatz J. L. (2008) Adsorptive effects of di-tri-octahedral smectite on Clostridium perfringens alpha, beta, and beta- 2 exotoxins and equine colostral antibodies. Am. J. Vet. Res. 69, 233-239

Love S. (1992) Parasite-associated equine diarrhea. Compe. Cont. Educ. Pract. Vet. 14, 642-649

Ludwig K. G., Craig T. M., Bowen J. M., Ansari M. M. and Ley W. B. (1983) Efficacy of ivermectin in controlling Strongyloides westeri infections in foals. Am. J. Vet. Res. 44, 314-316

Lyons E. T., Drudge J. H. and Tolliver S. C. (2000) Larval cyathostomiasis. Vet. Clin. North. Am. Equine. Pract. 16, 501-513

Lyons E. T., Tolliver S. C., Collins S. S. and Drudge J. H. (2001) Transmission of endoparasites in horse foals born on the same pasture on a farm in central Kentucky (1996-1999). Vet. Parasitol. 97, $113-121$ 
MacKay R. J. (2001) Equine neonatal clostridiosis: Treatment and prevention. Comp. Cont. Educ. pract. vet 23, 280-285

Magdesian K. G. (2005) Neonatal foal diarrhea. Vet. Clin. North Am. Equine Pract. 21, 295-312, vi

Magdesian K. G., Hirsh D. C., Jang S. S., Hansen L. M. and Madigan J. E. (2002) Characterization of Clostridium difficile isolates from foals with diarrhea: 28 cases (1993-1997). J. Am. Vet. Med. Assoc. 220, 67-73

Mair T. S., Taylor F. G., Harbour D. A. and Pearson G. R. (1990) Concurrent cryptosporidium and coronavirus infections in an Arabian foal with combined immunodeficiency syndrome. Vet. Rec. $126,127-130$

Martirosian G., Rouyan G., Zalewski T. and Meisel-Mikolajczyk F. (1998) Dioctahedral smectite neutralization activity of Clostridium difficile and Bacteroides fragilis toxins in vitro. Acta Microbiol. Polon. 47, 177-183

Masri M.D., Merritt A.M., Gronwall R. and Burrows C.F. (1986) Faecal composition in foal heat diarrhoea. Equine Vet. J. 18, 301-306

McGurrin M. K., Vengust M., Arroyo L. G. and Baird J. D. (2007) An outbreak of Lawsonia intracellularis infection in a standardbred herd in Ontario. Can. Vet. J. 48, 927-930

Murray M. J. (1989) Endoscopic appearance of gastric lesions in foals: 94 cases (1987-1988). J. Am. Vet. Med. Assoc. 195, 1135-1141

Murray M. J. (2002) Medical disorders of the large intestine. In: Large Animal Internal Medicine, 3 edn., Ed: B.P. Smith, Mosby Inc., Missouri. 654-655

Nakagomi O. and Nakagomi T. (2002) Genomic relationships among rotaviruses recovered from various animal species as revealed by RNA-RNA hybridization assays. Res. Vet. Sci. 73, 207-214

Netherwood T., Binns M., Townsend H., Wood J. L., Mumford J. A. and Chanter N. (1998a) The Clostridium perfringens enterotoxin from equine isolates; its characterization, sequence and role in foal diarrhoea. Epidemiology and infection 120, 193-200

Netherwood T., Wood J. L., Mumford J. A. and Chanter N. (1998b) Molecular analysis of the virulence determinants of Clostridium perfringens associated with foal diarrhoea. Vet. J. 155, 289-294

Netherwood T., Wood J. L., Townsend H. G., Mumford J. A. and Chanter N. (1996) Foal diarrhoea between 1991 and 1994 in the United Kingdom associated with Clostridium perfringens, rotavirus, Strongyloides westeri and Cryptosporidium spp. Epidemiol. Infection 117, 375-383

Oftedal O. T., Hintz H. F. and Schryver H. F. (1983) Lactation in the horse: milk composition and intake by foals. J. Nutrition 113, 2096-2106

OHo P., Elschner M., Schulze P., Prudlo J. and Schrader R. (1997) Anwendung eines Schnelltests zum Nachweis von Rotaviren in Kotproben. Berliner Münch. Tierärztl. Wochschr. 110, 397-400

Ousey J., Holdstock P. and Rossdale P. (1996) How much energy do sick neonatal foals require compared to healthy foals? Pferdeheilkunde 12, 231-237

Palmer J .E. (2004) Fluid therapy in the neonate: not your mother's fluid space. Vet. Clin. North Am. Equine Pract. 20, 63-75

Palmer J. E., Benson C. E. and Whitlock R. H. (1985) Salmonella shed by horses with colic. J. Am. Vet. Med. Assoc. 187, 256-257

Paradis M. (2001) Nutrition and indirect calorimetry in neonatal foals. Proceedings of the 19th American College of Veterinary Internal Medicine Forum, Lakewood CO, 245-247

Paradis M. (2003) Nutritional support: enteral and parenteral. Clin. Tech. Equine Pract. 2, 87-95

Patole S. (2007) Prevention and treatment of necrotising enterocolitis in preterm neonates. Early Hum. Dev. 83, 635-642

Patterson-Kane J. C., Bain F. T., Donahue J. M. and Harrison L. R. (2001) Meningoencephalomyelitis in a foal due to Salmonella agona infection. New Zealand veterinary journal 49, 159-161

Pearson E.G., Hedstrom O.R., Sonn R. and Wedam J. (1986) Hemorrhagic enteritis caused by Clostridium perfringens type $C$ in a foal. J. Am. Vet. Med. Assoc. 188, 1309-1310

Peregrine A. S., McEwen B., Bienzle D., Koch T. G. and Weese J. S. (2006) Larval cyathostominosis in horses in Ontario: an emerging disease? Can. Vet. J. 47, 80-82
Ramey D. W. and Reinertson E. L. (1984) Sand-induced diarrhea in a foal. J. Am. Vet. Med. Assoc. 185, 537-538

Sampieri F., Hinchcliff K. W. and Toribio R. E. (2006) Tetracycline therapy of Lawsonia intracellularis enteropathy in foals. Equine Vet. J. 38, 89-92

Schott H. C., 2nd, Ewart S. L., Walker R. D., Dwyer R. M., Dietrich S., Eberhart S. W., Kusey J., Stick J. A. and Derksen F. J. (2001) An outbreak of salmonellosis among horses at a veterinary teaching hospital. J. Am. Vet. Med. Assoc. 218, 1152-1159, 1100

Schumacher J., Schumacher J., Rolsma M., Brock K. V. and Gebhart C. J. (2000) Surgical and medical treatment of an Arabian filly with proliferative enteropathy caused by Lawsonia intracellularis. J. Vet. Intern. Med. 14, 630-632

Simmer K. (2007) Aggressive nutrition for preterm infants--benefits and risks. Early Hum. Dev. 83, 631-634

Slovis N. (2003) Gastrointestinal failure. Clin. Tech. Equine Pract. 2, 79-86

Smets K., Shaw D. J., Deprez P. and Vercruysse J. (1999) Diagnosis of larval cyathostominosis in horses in Belgium. Vet. Rec. 144, 665-668

Snyder S. P., England J. J. and McChesney A. E. (1978) Cryptosporidiosis in immunodeficient Arabian foals. Vet. Patho.I 15, 12-17

Stubbings D. P. (1990) Clostridium perfringens enterotoxaemia in two young horses. Vet. Rec. 127, 431

Tillotson K., Traub-Dargatz J. L., Dickinson C. E., Ellis R. P., MorleymP. S., Hyatt D. R., Magnuson R. J., Riddle W. T., Bolte D. and Salman M. D. (2002) Population-based study of fecal shedding of Clostridium perfringens in broodmares and foals. J. Am. Vet. Med. Assoc. 220, 342-348

Weese J. S., Cote N. M. and deGannes R. V. (2003) Evaluation of in vitro properties of di-tri-octahedral smectite on clostridial toxins and growth. Equine Vet. J. 35, 638-641

Weese J. S., Parsons D. A. and Stämpfli H. R. (1999) Association of Clostridium difficile with enterocolitis and lactose intolerance in a foal. J. Am. Vet. Med. Assoc. 214, 229-232, 205

Weese J. S., Stämpfli H. R. and Prescott J. F. (2000) Survival of Clostridium difficile and its toxins in equine feces: implications for diagnostic test selection and interpretation. J. Vet. Diagn. Invest. 12, 332-336

Weese J. S., Stämpfli H. R. and Prescott J. F. (2001) A prospective study of the roles of clostridium difficile and enterotoxigenic Clostridium perfringens in equine diarrhoea. Equine Vet. J. 33, 403409

Weese J. S., Toxopeus L. and Arroyo L. (2006) Clostridium difficile associated diarrhoea in horses within the community: predictors, clinical presentation and outcome. Equine Vet. J. 38, 185188

Wehrli Eser M., Feige K., Fuerst A., Kummer M., von Bomhard W. and Philipp M. (2002) Nekrotisierende Kolitis bei einem maturen neugeborenen Fohlen. Pferdeheilkunde 15, 451-456

Wilkins P. A. (2004) Disorders of foals, 2 edn., Saunders, St. Louis, Missouri 63146.1381-1431

Williams N. M., Harrison L. R. and Gebhart C. J. (1996) Proliferative enteropathy in a foal caused by Lawsonia intracellularis-like bacterium. J. Vet. Diagn. Invest. 8, 254-256

Xiao L. and Herd R. P. (1994a) Epidemiology of equine Cryptosporidium and Giardia infections. Equine Vet. J. 26, 14-17

Xiao L. and Herd R. P. (1994b) Review of equine Cryptosporidium infection. Equine Vet. J. 26, 9-13

Bettina Dunkel, DVM, DACVIM, DACVECC

The Royal Veterinary College

Department of Veterinary Basic Sciences

Hawkshead Lane,

North Mymms

Herts AL9 7TA

United Kingdom

bdunkel@rvc.ac.uk 